Revista Española de Antropología Americana ISSN: 0556-6533

http://dx.doi.org/10.5209/reaa.71746

\title{
Tiempos cristianos y tiempos andinos en las crónicas coloniales y los qeros $^{1}$
}

\author{
José Luis Martínez C. ${ }^{2}$
}

Resumen. Un conjunto de qeros andinos de los siglos XVII y XVIII, que muestran escenas correspondientes al pasado andino y a su presente colonial, permiten abordar la discusión acerca de los distintos conceptos de tiempo y espacio que tenían tanto las sociedades cristianas europeas de la época como la andina. En tanto que en las primeras ambos conceptos son autónomos, en los Andes el concepto de pacha supone la simultaneidad de tiempo y espacio. Mientras las crónicas escritas por europeos se organizaron con una concepción lineal del tiempo, las narraciones visuales en los qeros siguieron principios organizativos y enunciativos distintos. Se propone que ambos conceptos coexistieron colonialmente, y sirvieron de base para la construcción y/o conservación de las memorias en los Andes.

Palabras clave: tiempo; espacio; Pacha; crónicas; qeros; sociedades andinas; período colonial.

\section{[en] Christian Times and Andean Times. Colonial Chronicles and Qeros}

\begin{abstract}
A set of Andean qeros from the 17th and 18th centuries, which show scenes corresponding to the Andean past and its colonial present, allow us to approach the discussion about the different concepts of time and space that both the European Christian societies of that time and the Andean ones had. While in the former both concepts are autonomous, in the Andes the concept of pacha implies the simultaneity of time and space. While the chronicles written by Europeans were organized with a linear conception of time, the visual narratives in the qeros followed different organizational and enunciative principles. It is proposed that both concepts coexisted colonially, and served as the basis for the construction and/or conservation of memories in the Andes.
\end{abstract}

Keywords: time; space; Pacha, chronicles; qeros; andean societies; colonial times.

Sumario. 1. Un vaso colonial. 2. Los qeros coloniales. 3. Tiempo europeo cristiano - Pachas andinos. 4. Los qeros y la narración visual andina. 5. Conclusiones. 6. Referencias.

Cómo citar: Martínez C., José Luis. 2020. "Tiempos cristianos y tiempos andinos en las crónicas coloniales y los qeros”. Revista Española de Antropología Americana 50: 81-102.

\footnotetext{
1 Este trabajo es resultado del Proyecto FONDECYT 1130431 y fue presentado, en una primera versión, en el Simposio "Epistemologías transculturales. La producción de conocimientos en zonas de contacto en América Latina", Berlín, Ibero-Amerikanisches Institut, 1 y 2 de diciembre de 2016.

2 Centro de Estudios Culturales Latinoamericanos, Departamento de Ciencias Históricas, Universidad de Chile. jomarcer@u.uchile.cl.
} 


\section{Dedicado a Franklin Pease, para quien el problema del registro temporal de las sociedades andinas fue un desafio que exigía otras formas de comprensión.}

\section{Un vaso colonial}

En la colección de vasos y copas de madera coloniales del Museo de Metales Preciosos de La Paz (MMP-La Paz), se encuentra una pieza que capta de inmediato la atención del visitante, tanto por su forma como por su bella decoración; me refiero a la pieza CFB 3540 (Figura 1) ${ }^{3}$. Aunque inicialmente se la pueda reconocer como una copa, esto es, un recipiente ancho sobre un pedestal y una base circular más reducida, el contorno levemente "arriñonado" del recipiente no corresponde a las copas coloniales más comunes, usualmente redondas, sino que parece reproducir un diseño que se remonta hasta la cultura Tiawanaku, en la que se encuentran esas mismas formas "arriñonadas", esta vez en vasijas de cerámica ${ }^{4}$. No se trata de una pieza única. Se conocen, al menos, otras seis con la misma morfología ${ }^{5}$, y ésta a la que me refiero parece provenir ya sea de Copacabana o de alguna de las localidades del borde sur oriental del Lago Titikaka ${ }^{6}$. Se podría pensar, al menos como simple hipótesis, que los artesanos que la hicieron estaban relativamente familiarizados con la cerámica Tiawanaku, lo que no es arriesgado postular asumiendo que en los siglos XVII o XVIII (en los que podría haberse hecho nuestra copa) los objetos provenientes de Tiawanaku tenían un cierto prestigio cultural.

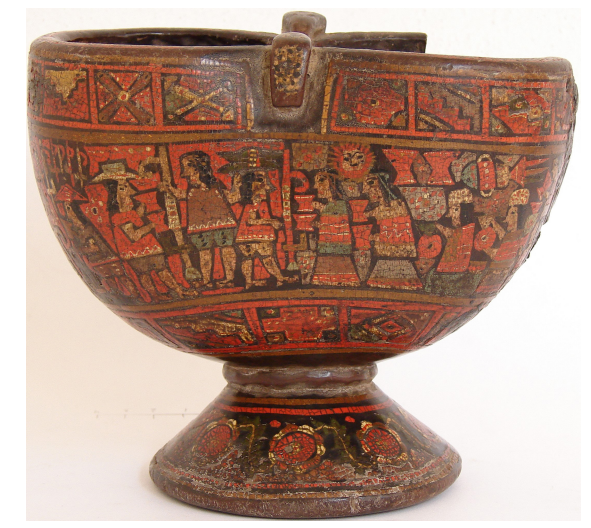

Figura 1. Copa CFB 3540. Copa "arriñonada" con técnica decorativa de los qeros (fotografía del autor).

3 El primer trabajo sobre esta pieza, corresponde a una publicación de Flores et al. (1997), en el que se postula que podría pertenecer a una tradición altiplánica, posición que compartimos. También Ziólkowski et al. (2009) la menciona brevemente, a propósito de sus diseños de tocapus.

4 Véase, por ejemplo, la ilustración $N^{\circ} 44$, de una pieza procedente de la isla Pariti, en Korpisaari y Pärssinen (2005). Si bien los autores señalan que no era una forma corriente, si se registran otros ejemplares similares en las colecciones del Museo Nacional de Arqueología de Bolivia (en adelante, Munarq). Flores et al. (1998: 65) señalan igualmente esta posible asociación morfológica.

5 Las piezas MAM 7562, del Museo de América (Madrid), 163 MV, del Museo arqueológico de la Universidad Nacional de San Agustín (Arequipa) y ML 400681, del Museo Larco (Lima). Otárola (1995: 69-709) publica el dibujo de otra pieza, procedente del Museo Inka (Cuzco) que también está fotografiada en Flores et al. 1998: 65. Estos mismos autores publican otros dos ejemplares de copas arriñonadas, igualmente del Museo Inka (ibíd:: 232 y 331).

6 Al menos una parte importante de las piezas de la colección Fritz Buck fueron adquiridas en esa zona, según los registros del mismo Buck. 
Pero no es la forma lo único que llama la atención en esta pieza. Me parece que lo más relevante es la decoración de su superficie. En cada uno de sus lados aparece una escena distinta. En uno de ellos (el que está completo puesto que en el otro falta un gran pedazo), está grabada y pintada una escena que representa a un grupo de hombres y mujeres, en trajes andinos coloniales, participando de un ritual agrícola (Figura 2). En una parte de esta escena varios hombres que manejan chaquitajllas o arados andinos acabados en punta, se muestran con el pelo largo suelto distintivo de las sociedades andinas coloniales, visten camisetas cortas hasta un poco más abajo de la cintura, y llevan pantalones a la rodilla, abotonados; sus trajes se completan con sombreros de ala ancha. En la otra parte de esta escena aparece un grupo de mujeres, ataviadas con el traje prehispánico que muchas de ellas llevan hasta el día de hoy. Una larga tela que envuelve el cuerpo, aqsu o anako, las cubre, y sobre sus hombros llevan llijllas o mantillas. Al menos dos de ellas tienen el pelo negro y largo, aparentemente amarrado con hilos que recuerdan a las actuales tullmas, o cordones de lanas trenzados, con los que las mujeres jóvenes se amarran las trenzas en Bolivia. Otras dos llevan un sombrero o tocado semi redondo en su cabeza. Este sombrero, como las tullmas, parecen indicar una pertenencia altiplánica (¿aymara?) de sus portadoras. Algunas mujeres aparecen en actitud de ofrecer a los hombres pares de vasos de madera o qeros, en los que era usual beber chicha en los momentos rituales. Otras están tocando un pequeño tamborcillo de mano, o tinya, un instrumento circular usado por las mujeres en las fiestas rituales. Toda la escena así como la contrapuesta, que a continuación tratamos, está enmarcada en su parte superior e inferior por sendas bandas de diseños rectangulares que parecen corresponder a un tipo de tocapus ${ }^{7}$.

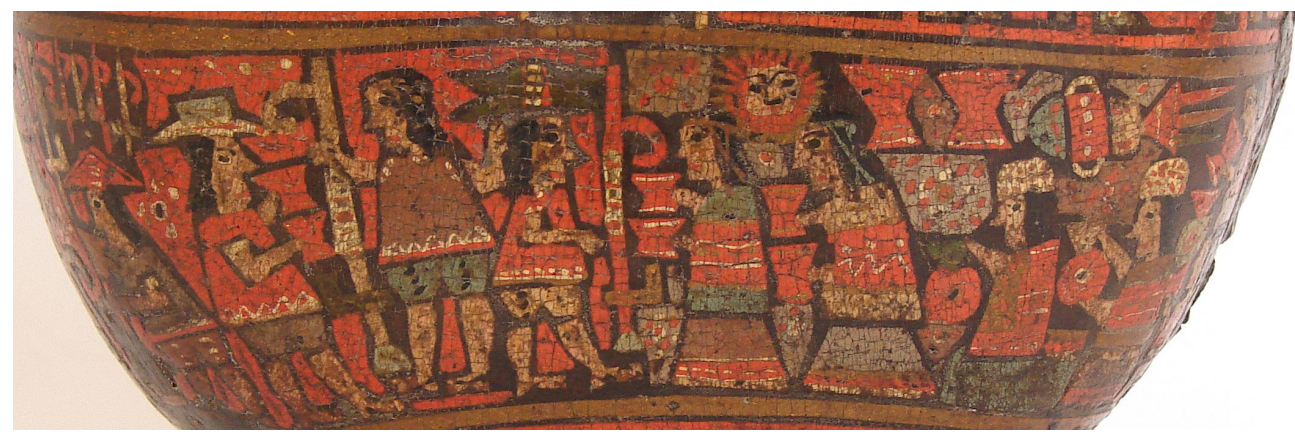

Figura 2. Copa CFB 3540. Detalle de una de las caras con escena de ritual agrícola colonial.

En la otra cara de esta copa "arriñonada" se grabó y pintó una escena completamente distinta. Ahora se trata de un espacio selvático, denotado por una gran palmera central que separa a dos grupos de guerreros, todos vestidos con trajes prehispánicos (Figura 3). Lamentablemente falta un fragmento que se ha perdido en el lado derecho, y únicamente se pueden identificar dos soldados cuzqueños que se enfrentan a un grupo de indios de la selva, chunchos o antis. Se trata de un tema colonial de amplia distribución en otros objetos de madera: los qeros, los vasos usados para los brindis rituales, que continuaron circulando durante la Colonia. Lo que se representa es una escena de enfrentamiento en tiempos de los inkas, entre tropas cuzqueñas y

Véase el trabajo de Ziòlkowski (2009) sobre los tocapus en los qeros. 
antis o chunchos, nombres genéricos dados a los habitantes de las tierras bajas de los Andes orientales. El único guerrero cuzqueño que queda íntegro luce el típico chuco o casco redondo de los ejércitos inkaicos, viste un largo unku cuzqueño ${ }^{8}$ decorado con una banda central de tocapus, y porta la pullqanqa o escudo de madera y lana en uno de sus brazos, mientras que en el otro sostiene una lanza emplumada. Sobre su cabeza se advierte un escudo de un segundo soldado inkaico. Los cuzqueños se enfrentan a cinco guerreros antis, armados de arcos, flechas y mazas con puntas, que visten trajes de pieles moteadas de felino y llevan tocados de plumas en sus cabezas. Uno de los combatientes antis aparece semi transformado en ave, volando sobre las cabezas de sus compañeros.

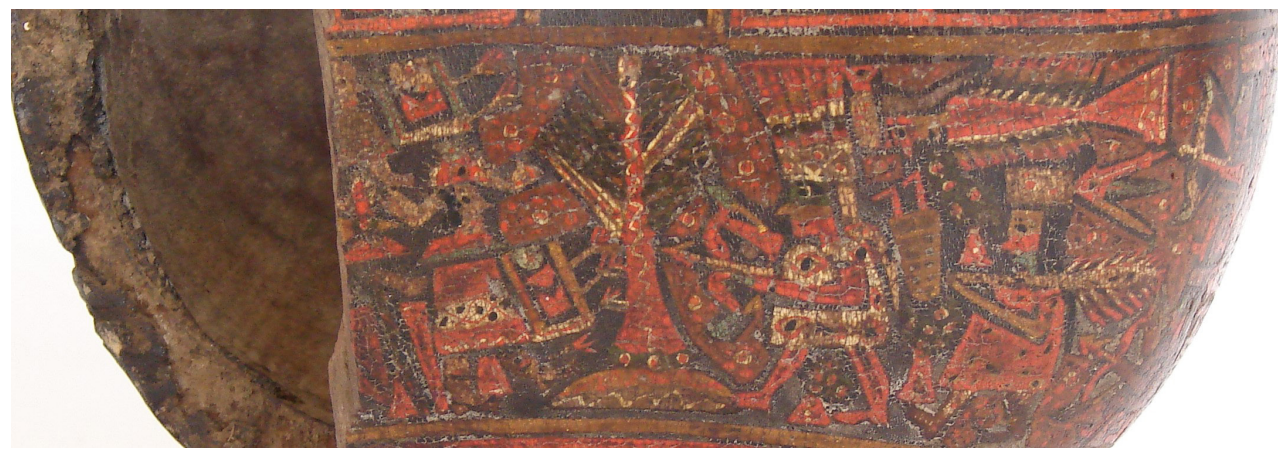

Figura 3. Copa CFB 3540. Detalle de la otra cara con escena de enfrentamiento entre guerreros cuzqueños y antis o chunchos.

Esto es lo sorprendente de esta copa: la coexistencia en ella de dos escenas que representan momentos temporalmente distintos y sin relación mutua. No se trata de una novedad en los registros visuales andinos coloniales. He podido identificar al menos otros diez recipientes usados para brindis rituales con una característica similar9. Pasado y presente conviven en las piezas a través de las formas y de las imágenes. El objeto, en su forma, recuerda un modelo prehispánico; y en su decoración, muestra técnicas desarrolladas fundamentalmente a partir del siglo XVI y temas que representan dos períodos históricos distintos. Esta "convivencia" de dos escenas que remiten a tiempos históricos diferentes, no parece estar organizada como una secuencia, en la que primero se narra un tema perteneciente al pasado de algún sujeto o grupo y, después, otro en el que se relata el presente de ese mismo sujeto o grupo, como resultado de una acción o evento pasado. Así sería, al menos, en un relato o historia basado en una temporalidad lineal del tipo cristiano occidental, en el que el presente es consecuencia del pasado y una misma narrativa puede unir ambos tiempos pero con una relación de continuidad y de explicación. Nada de esto parece ocurrir en esta copa.

$8 \quad$ Es el largo del vestido masculino, el unku y no su forma, lo que permite adscribirlo como prehispánico o colonial. A partir de la introducción de los pantalones europeos, el unku se fue acortando paulatinamente, hasta transformarse en una camisa larga (Phipps 2005).

9 Me refiero tanto a qeros, propiamente tales como a paqchas. Se trata de las piezas NMAI 16/6131 y 15/2410, del National Museum of American Indian; BM 42.149, del Brooklyn Museum; Va 28404, del Ethnologisches Museum; la pieza MChAP 3347 del Museo Chileno de Arte Precolombino; el vaso MI-momac 2379, del Museo Inka; otras dos, publicadas por Liebscher (1986: 35, 40, del Museo Inka 3948-110 y del Reiss-Museum Mannheim) y Otárola (1995: láminas 12 y 13). 
La voluntad de marcar la diferencia de ambos relatos y de sus respectivas temporalidades es evidente en otros detalles. Una clara línea divide verticalmente ambas caras, separando las dos escenas (Figura 4), y en el pie del pedestal se marcó la misma diferencia, esta vez grabando y pintando dos series distintas: del lado del ritual de agricultura, se representó una serie de flores conocidas como chimpu-chimpu; del lado del enfrentamiento de los inkas con los chunchos o antis, se representó una serie de aves, posiblemente picaflores, apuntando al centro de unas flores. Así, pasado y presente coexisten en un mismo objeto, pero no constituyen el uno un antecedente del otro. Me parece importante destacar que el principio de separar ambos tiempos o escenas por una clara divisoria (ya sea una línea o un relieve, vertical u horizontal, ver Figura 4a), se utilizó igualmente en otros cuatro de los ejemplares mencionados anteriormente, y está presente asimismo en el dibujo "Pontifical Mundo" de Guaman Poma (Figura 4b), en la que aparecen dos escenas que corresponden la una, al tiempo de los inkas, y la otra, al tiempo colonial (Guaman Poma 1616: f. 42).
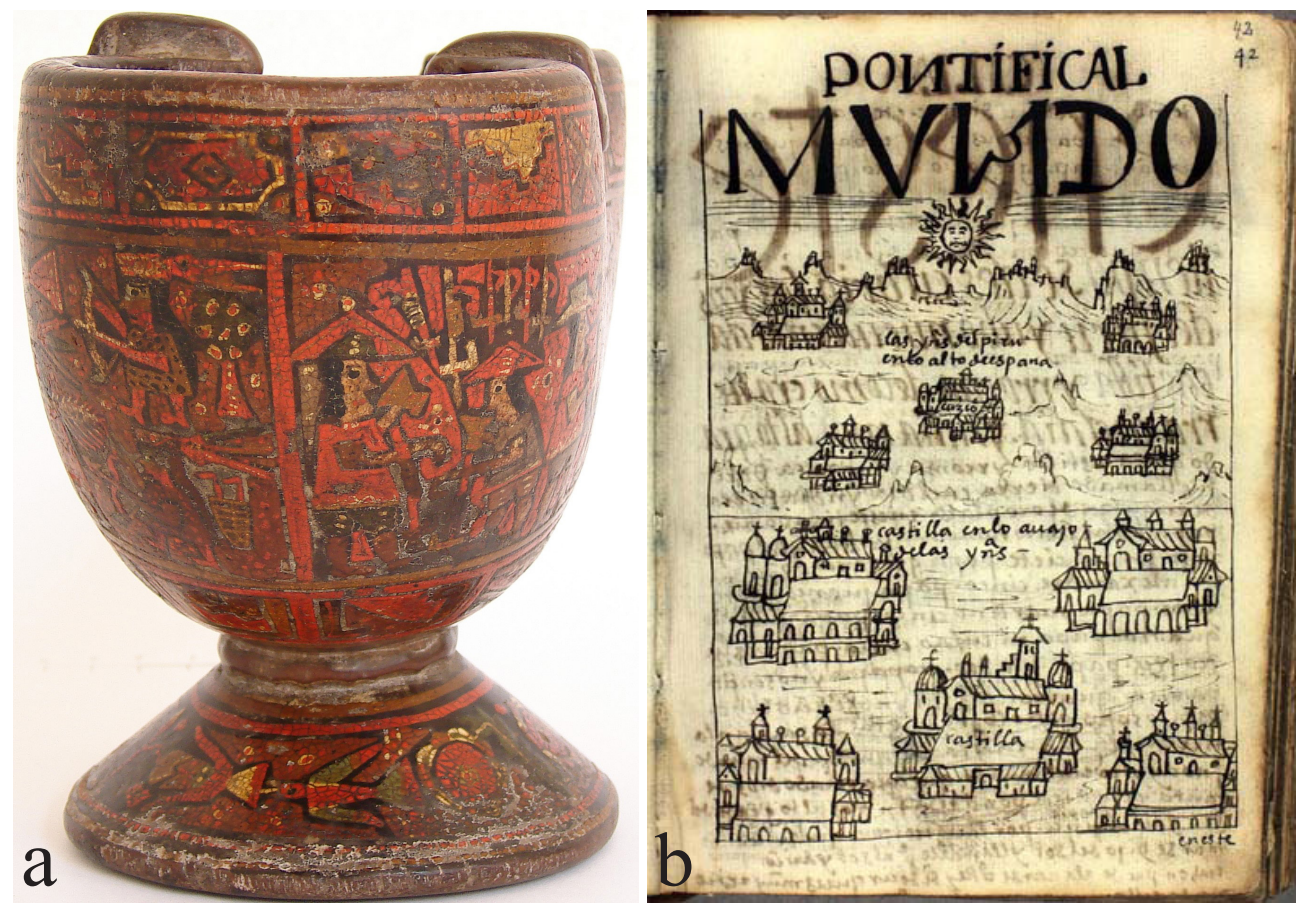

Figura 4. a) Copa CFB 3540: línea vertical divisoria de ambas escenas (en rojo) y base del pedestal. A la derecha se ve una flor redonda, chimpu-chimpu, y a la izquierda un ave con el pico hacia el centro de la flor; b) "Pontifical Mundo", en el capítulo de los papas y sus reinados (Guaman Poma 1616: f. 42. Publicación autorizada por la Royal Danish Library).

Mi interés por esta pieza surge porque los motivos pintados en su superficie no eran únicamente una decoración, sino que constituían textos visuales, con una narrativa propia y autónoma, elaborada por artesanos andinos para dar cuenta ya sea de la vida colonial, así como de una memoria - construida colonialmente- sobre el pasado prehispánico. Se podría decir, entonces, que esta copa es un documento que forma parte de un archivo disperso a lo largo y ancho de muchos museos y colecciones particulares. Un conjunto de textos visuales que, reunidos, nos podrían dar una 
muestra mucho más contundente y diversa del pensamiento de esos seres humanos que el conjunto de láminas dibujadas en los textos de Felipe Guaman Poma de Ayala y del mercedario fray Martín de Murúa. Se trata de documentos andinos coloniales que usaron lenguajes diferentes a los de la escritura alfabética y que, por lo tanto, requieren de la construcción de una teoría sobre su funcionamiento y de una metodología que nos permita, paulatinamente, ir comprendiéndolos en sus estructuras de producción de significación para lograr una mejor lectura de ellos.

\section{Los qeros coloniales}

Antes de continuar, sin embargo, es necesario discutir algunos aspectos de estos vasos, para una mejor comprensión de la problemática que quiero plantear aquí. Los vasos de madera o qeros formaron parte de un sistema de comunicación prehispánico, de larga data y desarrollo en muchas de las sociedades andinas incluso anteriores a los inkas.

Un rasgo importante de estos vasos es que formaban parte del conjunto de emblemas de las autoridades andinas, fueran hombres o mujeres. Eran esenciales en los rituales de ofrecer y compartir bebida (una de las prácticas más centrales en la etiqueta de reciprocidad del poder andino), y permitieron simbolizar el establecimiento de alianzas y relaciones de dominio o subordinación, así como también fueron empleados para rememorar determinados acontecimientos que formaban parte de las memorias políticas de los señores o gobernantes (Cummins 1998). Durante el período colonial, si bien continuaron inicialmente muy ligados a esos mismos rituales de poder, surgieron importantes cambios. De hecho, y a diferencia de los qeros prehispánicos, los coloniales no fueron enterrados como parte de las ofrendas funerarias que acompañaban a los grandes señores andinos ${ }^{10}$; más bien, la mayoría de los vasos de madera que conocemos continuaron en uso a lo largo de todo el período colonial e incluso del republicano, hasta que empezaron a ser adquiridos por coleccionistas y museos como objetos representativos del pasado inkaico.

En ese camino de cambios y transformaciones, su uso parece haberse ampliado y socializado, dejando de ser de posesión casi exclusiva de los miembros de las élites andinas. También a lo largo de la época colonial, algunos fueron elaborados como objetos de consumo para un mercado interesado en los objetos de estatus, además de ser bellos y tener valor comercial (Cummins 2004).

Los mayores cambios ocurrieron sobre todo con la incorporación de nuevos temas narrativos ${ }^{11}$ y una iconografía que incorporó imágenes europeas o las adaptó para nuevos usos comunicacionales. El empleo de lenguajes visuales figurativos y del color ya estaba presente anteriormente tanto en los qeros inkaicos como en la cerámica y, por supuesto, en el arte rupestre. Durante el Tawantinsuyu, los artesanos que los realizaron - qerukamayoq o "carpinteros" en una traducción colonial- habían alcanzado un gran dominio técnico, desarrollando un lenguaje visual muy regulado y sistematizado que combinaba elementos abstractos con algunos figurativos. Aparentemente hacia finales del estado inkaico, en los momentos previos a la invasión

10 Hay excepciones, claro, como el caso de los qeros encontrados en tumbas subterráneas en la actual comunidad de Soraga (Mora y Goytia 2016).

11 Para una identificación y caracterización de los diferentes temas o motivos de las escenas de los qeros, véanse los estudios de Liebscher (1986), Flores et al. (1997, 1998), Ramos (2001, 2002, 2008) y Cummins (2004). 
europea, se empezó a incluir en esos mismos vasos algunas figuras de animales y otros signos, que ahora no solo serán grabados sino también pintados. Todo parece indicar que, con posterioridad a la derrota ante los europeos, los qeros adquirieron un protagonismo sorprendente como soportes de nuevas narrativas y mensajes, con lenguajes plásticos que incorporaron gran cantidad de elementos figurativos europeos e, incluso, algunos aspectos estructurales de la visualidad cristiana europea de la época (Cummins 1993, 2005; Lizárraga 2009, 2015). Rápidamente se impuso un tipo de relato figurativo, muchas veces naturalista, en el que es posible reconocer paisajes, personajes y acciones, que desplazaron el anterior predominio de los elementos abstractos, aunque no los eliminaron completamente.

Es posible entender este inusitado desarrollo de la narrativa visual de los qeros como parte de los procesos sociales de profundos cambios y transformaciones que trajo la imposición del sistema colonial. En ese contexto, las poblaciones andinas acudieron a sus sistemas tradicionales de registro y comunicación, adaptándolos a las nuevas circunstancias y necesidades. Se trata de un proceso que involucró a un conjunto más amplio de sistemas andinos de registro y comunicación, con sus respectivos soportes. Esta continuidad y despliegue de nuevos registros, con un tipo similar de cambios, está registrada igualmente para el arte rupestre colonial (Strecker y Taboada 2007, entre otros) y para los khipus (Curatola y de la Puente 2013), así como para algunas formas de representaciones músico-coreográficas, como las "historias de los inkas" (Husson 2001; Martínez C. 2019). Así, y a pesar de la avasalladora irrupción e imposición de los sistemas de registro europeos, en particular de la escritura alfabética y de los lenguajes plásticos propios de la tradición europea cristiana ${ }^{12}$, se puede afirmar que muchos de los sistemas prehispánicos continuaron funcionando y siguieron siendo un vehículo importante para la circulación de las voces locales y la construcción de pensamientos, ideas y nuevas epistemologías a lo largo de gran parte del período colonial.

Esto es de gran importancia, puesto que cambia una de las maneras de entender los procesos de construcción de lo colonial, en los Andes al menos, ya que rompe con una cierta mirada unilateral que privilegió el análisis de la incorporación de los indígenas a los sistemas comunicativos europeos (y los procesos de mestizaje que aparecen asociados) olvidando o minimizando la importancia de la permanencia de los sistemas andinos. Permite, en otras palabras, romper con un cierto silencio comunicativo que se había supuesto para esas mismas poblaciones andinas coloniales.

Sabemos que, con diferentes grados de control y orientación, pero también con una cierta autonomía creativa, las sociedades andinas se incorporaron al empleo de los sistemas de registro europeos. La proliferación de la pintura indígena en iglesias y cuadros, así como el dominio de la escritura alfabética por parte de caciques y otros indígenas que participaron en cofradías y talleres de escritura ${ }^{13}$, muestra efectiva-

12 Para el tema de la escritura alfabética y la desvalorización de los sistemas orales o de otros registros gráficos, véase Gruzinski 1991, Mignolo 1992 o Salomon 1994. Para el caso de los lenguajes visuales europeos, véanse Gruzinski 1994 y Estenssoro 2005.

13 Ossio (2008: 16 y ss.) retoma la afirmación de Cárdenas (1998, apud Ossio 2008), acerca de que en el manuscrito de Guaman Poma de Ayala intervinieron a lo menos tres manos, lo que se reproduce también en la redacción del manuscrito Galvin del texto de Martín de Murúa (2004). Para un análisis más detallado de estos y otros posibles talleres de escritura coloniales con participación de indígenas andinos, véase el trabajo de Martínez S. (2016). La extensa correspondencia de varias autoridades, como Diego Chambilla, mallku de los lupaqas del lago Titikaka, recientemente publicada en Sucre (Medinaceli e Inch 2010), también apunta en la misma direc- 
mente la importancia y la posición dominante de esos sistemas también al interior de las comunidades andinas o de ciertos grupos de ellas.

Pero paralelamente siguieron funcionando también esos otros sistemas nativos, a veces incluso como complemento de los sistemas europeos, como lo muestra el uso judicial de los khipus durante el siglo XVI (Pärssinen y Kiviharju 2004, 2010), o de algunos de los bailes y teatralidades en el contexto de las fiestas patronales y la evangelización (Estenssoro 1992), pero también al margen de ellos, como el arte rupestre colonial (Martínez C. 2009). En lo que respecta a los qeros, parecen haber tenido una importante cuota de autonomía y circularon, más o menos libremente, con algunos episodios represivos ${ }^{14}$, aparentemente tanto en contextos urbanos como al interior de algunas comunidades de la zona del Cuzco, del borde suroriental del lago Titikaka y en parte de la sierra y el altiplano.

Como se ve, mi posición no es postular una continuidad de los sistemas de registro y comunicación andinos prehispánicos, ahora en un contexto colonial, sin cambios o adaptaciones a la nueva situación, o como instrumento de una resistencia pertinaz frente a lo europeo ni, mucho menos, discutir o minimizar la fuerte influencia de los sistemas europeos tanto en el surgimiento de nuevos espacios de producción y circulación, como en las formas de pensar y comunicar ideas. Muy por el contrario, lo que hace apasionante el estudio de los sistemas como los khipus, los qeros o el arte rupestre, por nombrar algunos, es su enorme versatilidad, su flexibilidad para incorporar los nuevos elementos coloniales, por empaparse de imágenes y códigos ajenos, manteniendo al mismo tiempo una relación estrecha con sus productores y sus espacios de circulación, y conservando también algunas de sus propias lógicas organizadoras y sus ontologías, las cuales no eran las mismas que las de los europeos. Y así ocurría, por ejemplo, con el concepto de tiempo, lineal para éstos, y vinculado al espacio para los andinos.

\section{Tiempo europeo cristiano-Pachas andinos}

Es necesario, sin embargo, introducir una nota de cautela antes de continuar. En toda sociedad conviven diversas maneras de percibir, ordenar y significar la experiencia humana sobre el tiempo y el espacio (Carbonell 2004). Además de conceptos ontológicos tales como "tiempo" o "espacio", coexisten calendarios solares y lunares, o puede emplearse la posición de algunas estrellas o constelaciones en el cielo anual, todo lo cual permite un despliegue de ritmos diversos, de experiencias y de sus registros. Al tiempo lineal europeo le acompañaban el tiempo cíclico de los rezos del día o de las estaciones, el de los signos zodiacales; todo ello sin contar con los tiempos sagrados o profanos que también organizan parte de los quehaceres de cada sociedad y de su experiencia. Algo similar a lo que acontece con el espacio en diferentes sociedades. Aquí, de lo que se trata en este caso es del tiempo como ordenador de los relatos en textos ya sea escritos (europeos) o visuales (andinos).

Los relatos europeos (como las crónicas y memoriales), estaban sometidos a un conjunto de exigencias, requeridas para hacer de ellos una construcción narrativa que fuera reconocida como válida. La secuencia temporal "pasado-presente-futuro"

ción de una mayor participación andina en la escritura colonial.

14 Flores et al. (1998: 42 y ss.) hacen una breve síntesis de la represión que sufrieron los qeros entre los siglos XVI y XVIII en el área próxima a Cuzco. 
es la más recurrente de ellas y, al mismo tiempo, más "invisible" en el sentido de que escapa a la discusión o reflexión de esos autores (Mendoza 2015). El anónimo redactor en castellano de la Relación dada por los quipucamayos a Vaca de Castro, escribió que ninguno de los participantes andinos supo "dar otra razón más que todos los ingas fueron descendientes de Mango Cápac, que fue el primer inga" (Quipucamayos... 2004: 361; énfasis del autor); y Sarmiento de Gamboa afirmó que le fue encargado por el Virrey Toledo para que "hiciese la historia de los hechos de los doce ingas desta tierra y del origen de los naturales della hasta su fin" (2001: 23; énfasis del autor). En ambos casos, la secuencialidad, ya sea de la descendencia del primer inka o el origen de los naturales y su desarrollo "hasta su fin", es claramente una estructura temporal que organiza la narración, previa a su fijación por escrito. Cuando ellos escribieron, no remarcaron que estaban, simplemente, imponiendo una secuencia de continuidad que era aceptada como la más natural.

Un simple contraste: los redactores en quechua del texto conocido como Manuscrito de Huarochirí escribieron, "No sabemos muy bien si éste [Cuniraya] existía antes o después [de Huallallo] y de Pariacaca" (Taylor 1987: 1:15:49; énfasis del autor). No se trata de desconocimiento o incapacidad; simplemente sucede que la secuencia temporal europea carecía de significado para las formas de ordenamientos temporales andinas. En el Lexicón de fray Domingo de Santo Tomás, impreso en 1560, aparece la voz "antecesor, ñaupaquenc" (1951: 41), es decir, lo que está antes de algo; y en 1586, el Arte y Vocabulario de la lengua quechua, traducía "ñaupa ñaupa" como "en tiempos pasados" y "ñaupa, ñaupapacha, En tiempos pasados" (Anónimo 2014: 137). La diferencia profunda consiste en que ñawpa posee la misma raíz de ñawin, ojos y, en consecuencia, está físicamente ubicado adelante del enunciante y no a sus espaldas, como ocurre con la ubicación corporal que se da en castellano al pasado, aquello que ya no se puede ver. De manera similar, en aymara, nayra (ojo) está relacionado con lo ya sucedido, con el pasado; en tanto que ch'ina (trasero) se vincula a lo que ocurrirá después, es decir, al futuro (Mendoza 2015: 183). Narrativamente, entonces, hay una diferencia profunda en el modo de construir los relatos ${ }^{15}$. Tal como lo destaca Hardman, refiriéndose al aymara,

"En Aymara el pasado está delante, bien visible, mientras que el futuro está detrás de uno, todavía no visible (fuera de lo que se pueda ver mirando por encima del hombro). Así que la distinción principal en los tiempos de los verbos es futuro y no-futuro (que contrasta con la europea que es pasado y no-pasado)" (Hardman 1988: 173).

Más aún, en quechua el término yuyay significa tanto memoria como pensamiento (Anónimo 2014: 182) ${ }^{16}$, por lo que, de acuerdo con Fernández "no existen diferencias conceptuales entre las acciones de pensar y recordar, que son contemporáneas.

15 Dejo fuera, por razones de extensión, el problema de la "evidencialidad" del enunciado, cuestión fundamental tanto en quechua como en aymara, que obliga al hablante a usar diversas conjugaciones de tiempo pasado para formular una oración. De allí la confusión de muchos cronistas dado que un mismo relato podía tener distintas conjugaciones de acuerdo al tipo de conocimiento (directo, presencial, indirecto, etc.) que tuviera cada uno de sus informantes; véase Hardman (1988) y Howard-Malverde (1988).

16 El campo semántico de este concepto es más amplio, implica también las características de la persona adulta, yuyac runa ("hombre adulto, de razón"), como a la imaginación (yuyacuni: estar pensando e imaginando algo"), entre otras acepciones posibles. 
Si "pensar" y "recordar" acaecen al mismo tiempo, entonces pasado y presente se mezclan" (2015: 119).

Ese supuesto "desorden" temporal de las narrativas andinas se origina, igualmente, en otra de las características del concepto andino del tiempo, pacha. Se trata de que lo que podríamos entender como pasado o tiempos antiguos, ancha ñawpa pacha o purum pacha, y presente, kay pacha, que no poseen el mismo ordenamiento secuencial del tiempo cristiano. Más aún, ambos tiempos pueden coexistir (Bouysse-Cassagne y Harris 1987). Mientras para los europeos de la época, el pasado quedaba atrás irreversiblemente y era sustituido o desplazado permanentemente por el presente, en términos andinos ambos momentos podían formar parte, contemporáneamente, de la experiencia de un individuo. Esto es posible porque pacha es tanto tiempo (si es posible darle esa connotación al término), como espacio, un tiempoespacio (Manga Quespi 1994: 157; Mendoza 2015: 181). De donde se sigue que cada tiempo ocupa un espacio que le es propio. Las tierras bajas del piedemonte oriental andino (los yungas, el antisuyu incaico) eran entendidas como un espacio de lo salvaje, lo pasado; lo mismo que algunos lugares muy altos, desolados, peligrosos; o los entornos carentes de luz. Todos ellos, por sus texturas, colores, dificultades visibles, etc. pueden ser entendidos como espacios de un pacha distinto o "anterior" al de la humanidad actual, pero al que es posible ir, en el que es factible estar (Cereceda 1990). El pasado no está, entonces, antes, sino que incluso puede estar "al lado" (véase Bouysse-Cassagne y Harris 1987), a diferencia de la ontología cristiana en la que pasado, presente y futuro suelen ocupar el mismo espacio variando únicamente su temporalidad.

Profundizando la tensión entre ambas ontologías del tiempo, es necesario recordar que la misma escritura alfabética tiene, en el simple acto de escribir, un profundo contenido temporal. En la parte superior se escribe el inicio, se da comienzo a una narración, se habla de lo primero; en la parte inferior se ubica el final, la consecución de lo ya iniciado más arriba. Cuando se pasan varias hojas o páginas, se "adelanta" o "retrocede" según la dirección del movimiento. Todo ello contribuye, adicionalmente, al esfuerzo de temporalizar, según la ontología cristiana, cualquier relato.

En este contexto, al menos en el siglo XVI, el orden de los capítulos debía ser secuencial y los "retornos" a eventos o momentos anteriores debían estar claramente justificados. En muchos textos escritos por europeos el relato se refiere únicamente a un tiempo, básicamente el pasado, para contar cómo eran los inkas y se detienen en el momento de la invasión; o relatan la vida colonial contemporánea, sin hacer referencia a las historias del pasado andino. Aunque es posible encontrar textos escritos con relatos sobre ambos tiempos, pasado y presente, usualmente uno de ellos cumple una función justificativa del otro: un breve relato del pasado para explicar las condiciones de la vida colonial, o una corta mención al presente, para cerrar el relato sobre el pasado. Los tiempos organizadores de los relatos no son autónomos en el sentido que lo son en las narrativas andinas, ya que aún en textos como el de Bernabé Cobo (1964), que abarca tanto el pasado pre-invasión como el presente colonial, están en una relación de continuidad, de una misma unidad narrativa.

En los relatos andinos, por el contrario, existe un modo narrativo que permite, concretamente, esa articulación "desordenada" que tanto molestó a los cronistas. Un ejemplo, en el mismo Manuscrito de Huarochirí se pasa sin explicación desde un tiempo que es descrito en el texto como purum pacha, donde las divinidades son protagonistas en los primeros 20 capítulos, al presente colonial (que se encuentra entre el capítulo 21 hasta el 27) en el que se relatan, sin ningún corte o explicación, 
un conjunto de situaciones de tiempo presente, para retomar, en el mismo capítulo 27, el relato sobre los tiempos pasados, tal como estaba al inicio del texto.

Quiero destacar aquí, nuevamente, otra diferencia. El futuro es el tiempo que organiza el sentido de la experiencia. Esta estructura triádica de organización de la experiencia humana en el tiempo es, asimismo, la base del cristianismo como religión (Finlay 1977), ya que el relato cristiano está orientado en una secuencia lineal "pasado" /origen-Paraíso/ "presente" /camino hacia la redención-este mundo terrenal/ "futuro" /salvación (cielo) o castigo (infierno).

Nada de ello ocurre en términos andinos porque, simplemente, el futuro no da sentido a la experiencia; si existe, consiste en la posibilidad del retorno de un pacha, distinto del actual, que podría provocar un pachakuti (una "vuelta" de tiempo). Este es un concepto que significa el desplazamiento de una humanidad, provocado por una divinidad o una autoridad sagrada (como los inkas) y su reemplazo por otra humanidad. Este reemplazo puede involucrar a una "nueva" humanidad o, la amenaza más frecuente, a otra que ya había sido desplazada y que retorna a una posición de centralidad. Los aymara desplazaron a los urus, en el altiplano, reemplazando de paso la luz lunar por una solar; la divinidad Pariacaca, en Huarochirí, derrotó a otra, Huallallo Carhuincho, provocando que toda esa humanidad huyera a refugiarse a la selva, y los ejemplos se multiplican ${ }^{17}$. Lo central aquí, como ya señalé, es que la estructura temporal cristiana, de tres tiempos o momentos significantes, estaba en contradicción con la andina, basada en dos momentos.

\section{Los qeros y la narración visual andina}

¿Cuáles fueron los dispositivos y los espacios y prácticas usadas por las sociedades andinas para conservar sus memorias y mantener las narrativas propias? Al menos, por parte de las distintas élites locales el proceso empezó tempranamente, de lo que han quedado diversos registros. En el Museo de América (MAM 07569, Madrid) hay una bella pieza, una paqcha (vaso usado para libaciones rituales agrícolas). En ella se muestra un desfile español y un arco iris que surge de las cabezas de dos felinos ${ }^{18}$; los soldados españoles están presentando armas y banderas a una figura mayor, un felino con incrustaciones metálicas que representan el moteado de su piel. Cabello (2006) postuló que esa escena daba cuenta de un evento ocurrido el 23 de febrero de 1537 en la costa norte peruana y que el cacique "homenajeado" por los soldados habría decidido "anotarlo a su manera". Aunque su confección parece posterior a esa fecha, muestra el registro de un momento importante para las memorias locales, al margen de los escritos europeos.

De acuerdo con un autor del siglo XVIII, en 1555, integrantes de la élite cuzqueña que residían en la ciudad de Potosí representaron públicamente varias escenas de la memoria sobre los inkas. Allí aparecieron todos los inkas que habían gobernado el Tawantinsuyu y se representaron varias de las conquistas consideradas más relevantes (Arzáns 1965). Casi contemporáneamente, se presentaron en distintas Audiencias

Ya en el siglo XVII hay registros de mitos que ubican a los inkas, una humanidad derrotada por los españoles, habitando espacios de la selva.

18 Puede accederse a información y fotografías de esta pieza a través del Catálogo en línea del Museo de América de Madrid (http://ceres.mcu.es/pages/Main) 
solicitudes de probanzas y memoriales, que buscaban, igualmente, mostrar o reclamar ante las nuevas autoridades coloniales el reconocimiento de los méritos hechos durante la invasión europea, o las grandes conquistas de los inkas. Entre 1558 y 1561, los señores wanka y xauxa de la sierra centro-norte del Perú presentaron al menos siete memoriales, basados en sus khipus, para exigir un reconocimiento de todo lo que habían hecho apoyando a los españoles contra los inkas y todo lo que los europeos les habían tomado durante las guerras contra los inkas de Vilcabamba (Parssinen y Kiviharju 2004: 155-246). Y en 1569, los descendientes de Thupaq Inka Yupanqui presentaron, a su vez, una petición de reconocimiento de derechos y privilegios por ser descendientes directos del Inka, a quien se le atribuía una parte importante de las conquistas inkaicas; para ello se basaron en un khipu en el que se detallaron con prolijidad los pueblos dominados y sus respectivas autoridades locales (Rowe 1985). Más al sur, en la Audiencia de Charcas, un grupo de mallkus, altas autoridades aymaras de la Confederación Qaraqara-Charka, presentaron en 1581 un extenso memorial en la misma línea que los anteriores (Platt et al. 2006).

Los esfuerzos por defender las memorias involucraron igualmente a varios españoles. En 1551, los parientes inkas de doña Angelina, coya y exmujer del inka Atawallpa, casada con Juan de Betanzos, le relataron su propia versión de la historia de los gobernantes cuzqueños (Betanzos 2015; Hernández 2015), y a finales del siglo XVI otros miembros de linajes cuzqueños le entregaron su versión a fray Martín de Murúa (Murúa 2004; Cummins y Ossio 2013).

Como se puede apreciar, los andinos apelaron tanto a sus propios soportes $(\mathrm{khi}$ pus, paqchas, representaciones músico-coreográficas) como a los europeos (documentos jurídicos y legales), y emplearon para ello diferentes lenguajes, visuales, musicales y táctiles, además de la escritura alfabética (Platt 2015). No se trataba de construir una única memoria. Me parece claro que las élites, ya fueran cuzqueñas o locales, también lucharon entre sí por imponer sus propias versiones. Durante la presentación de la historia incaica escrita por Sarmiento en 1572 en el Cuzco hubo una álgida disputa entre distintos bandos (Urbano 1997), y Urton (2004) ha mostrado los intentos del linaje de los Callapiña de apropiarse para ellos del mito de origen de los inkas en Pacariqtambo.

Me parece que, ahora, podemos volver a la copa arriñonada del Museo de Metales Preciosos y a los otros ejemplares mencionados, entendiéndolos como parte de los dispositivos a través de los cuales se expresaron esas sociedades andinas para conservar una cierta autonomía enunciativa, y que son expresivos de la construcción de un tipo de relatos que se organiza, precisamente, a partir del concepto de pacha y no del tiempo cristiano.

Señalé anteriormente que la cronología de estos vasos es importante para el análisis. En efecto, hasta donde podemos afirmarlo, las temáticas "históricas", esto es, aquellas referentes al "tiempo del inka" o a ñawpa pacha se desarrollaron desde finales del siglo XVI y a lo largo del resto de los siglos coloniales. Esto abarca el conjunto de qeros y otras formas de recipientes usados para los brindis rituales (copas o paqchas, por ejemplo), y al menos tres tradiciones estilísticas han sido identificadas ${ }^{19}$, lo que muestra una dispersión espacial que incluye, al menos, el área del Cusco y la cuenca del lago Titikaka. Las dataciones cronológicas por fechados

19 La tradición cuzqueña colonial, la tradición Omasuyos-lago Titikaka, y, finalmente, otra centrada en la ceja de selva del área de Charazani; véase Martínez C. et al. 2016b. 
radiocarbónicos que hemos podido obtener sugieren, por ahora, que el desarrollo de escenas narrativas acerca del "tiempo del inka" y del "presente colonial" cobraron fuerza a partir de finales del siglo XVI y en adelante. Se trataría, así, de narrativas posteriores al Virrey Toledo.

En una muestra de 476 de estos qeros y vasos o copas decorados que he podido estudiar hasta ahora, en la banda o campo superior de más de 350 de ellos se muestran escenas; esto es, se puede observar a un personaje o un conjunto de personas, realizando una acción; algo que está próximo conceptualmente a la pintura europea y colonial, pero que también se halla presente en el arte rupestre (tanto prehispánico como colonial) y en las narrativas orales o mito-historia (Urton 2004: 19).

Si se pudiera reunir todos los qeros conocidos, dispersos, como ya señalé, en varios museos y colecciones privadas, saltaría a la vista que ese gran conjunto tiene una característica interesante. Sus temas iconográficos pueden ser agrupados en los mismos dos grandes momentos temporales que identificamos en la copa arriñonada. Mientras unos contienen escenas pertenecientes a un pacha prehispánico (como la cara del enfrentamiento entre cuzqueños y antis o chunchos de la copa CFB 3540), los otros representan escenas o situaciones de la vida colonial (el ritual agrícola de la cara intacta de la misma copa). Hay en todos ellos una gran ausencia narrativa temporal: no se conoce o no ha sido descrito hasta ahora, ningún qero con temáticas que pudieran representar un tiempo futuro, el del triunfo de la fe cristiana u otro similar. Me parece que esto no es casual.

Entre las nuevas narrativas desarrolladas a partir del siglo XVII se encuentran rituales agrícolas y ganaderos, escenas de arriería y de bailes y comparsas, todo en un contexto colonial. Por otra parte, se puede identificar también un conjunto de escenas que remiten al pasado inkaico. Se encuentran aquí varias narraciones de algunos de los ciclos mito históricos más conocidos: representaciones de la expansión del Tawantinsuyu hacia las tierras bajas de los chunchos y los antis; del encuentro entre el Inka y el Qhapaq Qolla, el gobernante de los Collas en el borde nororiental del lago Tititkaka; de la defensa del Cuzco frente a la invasión de los chankas; del baile de la soga que se hizo para Titu Cusi Wallpa o Waskar Inka; de la o las varias guerras entre inkas; además de diversos rituales prehispánicos de limpia de canales y agrícolas. Y un grupo más reducido que muestra enfrentamientos entre andinos y españoles, en lo que parecen ser relatos de las batallas de la invasión europea a los Andes. Un antecedente no menor es que esos relatos visuales tienen correspondencia directa con los recogidos en las crónicas escritas por europeos durante la segunda mitad del siglo XVI. Entre ellos y las crónicas hay, entonces, un diálogo directo; lo que ocurre es que sus relatos difieren notablemente en cómo se construyen.

Aquí es necesaria una nota de cautela. De la muestra ya indicada, los once qeros en los que se basa mi análisis representan sólo un 3,2\% del total, lo que puede parecer muy poco significativo. Hay que destacar, sin embargo, que la dispersión de formas y temas es muy amplia, de modo que, por ejemplo, una forma muy característica de un tipo de qeros, los cefalomorfos ${ }^{20}$, representa tan solo un $6,4 \%$ de la misma muestra. Y temas como la guerra entre los inkas y los chankas, de gran importancia en la historia mítica cuzqueña, no alcanzan el 3\% de ella. Estos once vasos son aquellos que he podido identificar, lo que no excluye que haya otros en

20 Con forma de cabezas humanas o de felinos. 
museos y colecciones privadas a las que no he tenido acceso. Aun así, de lo que se trata de identificar aquí es si ellos utilizan, o no lo hacen, conceptos ontológicos como pacha, para organizar una narración visual. Por otra parte, nueve de estos vasos pueden ser adscritos a lo que conocemos como estilo cuzqueño colonial, y $\operatorname{tres}^{21}$ al estilo charazani, lo que sugiere una producción geográficamente más amplia, no restringida al área del Cuzco.

En los textos visuales que circularon en los qeros es posible advertir importantes diferencias respecto de los relatos de esos mismos temas, tal como ellos pasaron a los registros alfabéticos. En los qeros aparecen personajes que fueron eliminados de las "historias" quedando relegados a las "fábulas" (Martínez C. et al. 2014), y la configuración visual de las escenas se basa en el concepto de pacha, esto es, espacio y tiempo conjuntados. Una temporalidad que incluye, entre otros elementos, caracterizaciones ecológicas (correspondientes a los respectivos pacha), con flora y fauna asociadas de maneras mucho más compleja de las que se pueden advertir en las crónicas (Martínez C. et al. 2016a).

Como es de esperar, los modos narrativos, esto es, las maneras de articular los relatos, también difieren respecto de las crónicas. Se trata de modos en los cuales las narraciones lineales, con varias secuencias mutuamente interrelacionadas, tan características del ordenamiento temporal cristiano, no operan. Lo que encontramos, en cambio, es que a un tema central (por ejemplo, la conquista de los Antis) se le pueden agregar unidades de otros relatos (un ritual, por ejemplo); o se pueden presentar secuencias distintas de un mismo tema, que debieran -vistas desde una perspectiva occidental- estar separadas $u$ ordenadas de una manera secuencial y que en esos vasos no lo están. Otra de las modalidades es la de presentar simultáneamente en un mismo soporte los dos tiempos característicos de los relatos andinos; o, finalmente, reducir la narración más extensa a una presentación mínima, un pequeño fragmento de un relato mayor conocido por las audiencias que usaban esos vasos en sus brindis rituales (Martínez C. y Martínez S. 2013).

Los once ejemplares en los cuales se registraron, de manera simultánea, dos escenas correspondientes a distintos pacha corresponden al segundo de esos modos narrativos. En todos ellos se muestra un pacha, que podemos denominar ñawpa pacha, el tiempo que "ya se ha visto" (que corresponde colonialmente a la denominación "tiempo del inka"), con temáticas correspondientes a la historia de los inkas antes de la invasión europea; y otro, que corresponde al concepto de kay pacha, "este tiempo", con escenas de la vida colonial. Se trata del mismo tipo de escenas que se muestra en el resto del "archivo" de qeros, con la diferencia de que mientras en éstos las escenas corresponden únicamente a una u otra de esas categorías, en los del conjunto menor ambos tiempos coexisten.

Los modos de articulación de ambas escenas y sus temáticas no son siempre los mismos. Hay un modo de articulación "horizontal", en la que ambas escenas y pachas están, por así decirlo, en un mismo plano (Figura 5)22. En otros, la organización es "vertical" (Figura 6) ${ }^{23}$. El tiempo del inka o el colonial se distribuyen jerárquicamente en una relación "alto"/Hanan - bajo/Urin.

MI-momac 2379, MChAP 3347 y NMAI 152.410.

Ver MMP cfb 3540; EM Va 38404; NMAI 152.410 (Liebscher 1986: 40; Otárola 1995: lámina 12).

Ver BM 42.149; NMAI 166.131; MI-momac 2379. 

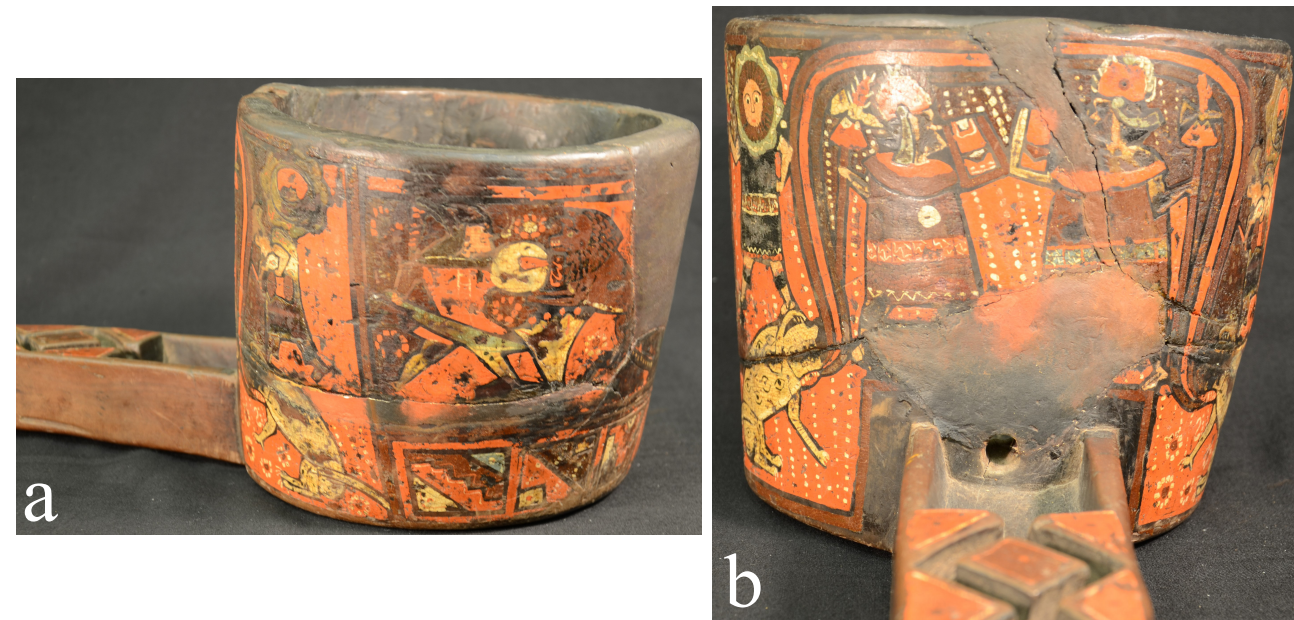

Figura 5. Detalle de la paqcha NMAI 152.410, estilo charazani: a) escena colonial con un soldado español, con coraza, escudo, yelmo y espada enfrentando un felino; b) escena del "Tiempo del Inka", muestra un enfrentamiento entre dos soldados cuzqueños, con emblemas inkaicos, bajo un arco iris que surge de las bocas de dos felinos (fotografías del autor).
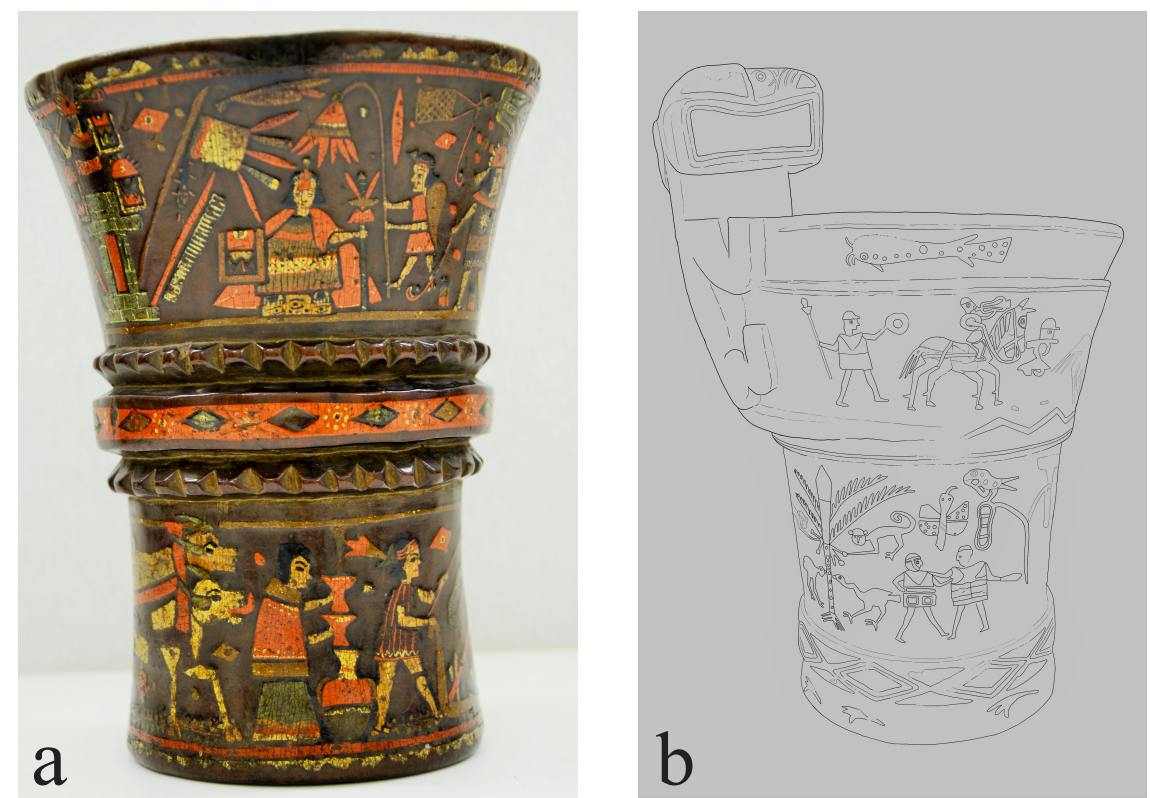

Figura 6. a) Qero BM 42.149, estilo cuzqueño. Escena superior o hanan: inka con mascapaicha, sentado en su tiana o asiento de gobernante. Escena inferior o urin: el tiempo colonial, con escena de agricultura (fotografía del autor, Proyecto Fondecyt 1130431); b) Detalle de qero (MI momac 2379) con escenas de dos tiempos. Campo superior: enfrentamiento entre combatientes andinos con trajes étnicos distintos y jinetes europeos armados con lanzas. Banda inferior: combate entre soldados andinos, acompañados por aves, monos y plantas tropicales (en ambiente de selva, purum pacha) que especifican características de ese espacio/tiempo o pacha (dibujo de Pablo Solar, Proyecto Fondecyt 1130431). 
Los qeros no son los únicos objetos que circulaban en la época de la Colonia con la representación de dos pachas simultáneamente. Se conoce al menos un unku colonial, la prenda de vestir masculina que continuó en uso por lo menos a lo largo del siglo XVI, que posee dos caras distintas ${ }^{24}$. Una de sus caras está cubierta de toqapus, los diseños geométricos abstractos que eran exclusivos de los linajes inkas del Cuzco y que parecen representar el kay pacha inka; la otra cara representa la piel moteada de un jaguar, un animal del Antisuyu, de los espacios no socializados y, por lo tanto, de purum pacha o awqa pacha, distintos o anteriores a los inkas. En el borde inferior de ambas caras, aparecen tejidos soldados inkas y guerreros antis o chunchus, remarcando el doble contenido de ambas caras ${ }^{25}$.

Lo sugerente en todos estos objetos es que se trata de una estructura significante y ordenadora, "pasado-presente", que se encuentra también en al menos un texto contemporáneo a los qeros, en la organización de la narración de la Nueva Corónica y Buen Gobierno de Felipe Guaman Poma (1616). En ésta, ese ordenamiento es explícito y evidente. Por una parte, una gran unidad referida a la memoria sobre el pasado prehispánico (la Nueva Corónica), que abre el relato sobre el mundo andino con la siguiente expresión: “ “. unas historias de nuestros antepasados agüelos y mis padres y señores rreys que fueron antes del Ynga y después que fue desde Uari Uira Cocha Runa y Uari Runa y Purun Runa» (Guaman Poma 1616: f. 6). Y la segunda parte, abocada a una descripción y denuncia de las condiciones de la vida colonial (el Buen Gobierno).

El concepto de pacha supone que cualquier presente puede transformarse en pasado, si un nuevo pacha (una nueva humanidad/tiempo) lo desplaza hacia la periferia, como en los casos que referí anteriormente. En el texto de Guaman Poma se encuentra ese mismo esquema de desplazamiento de pachas, el que también circuló colonialmente con el relato de los inkas "habitando" la mítica ciudad del Paititi en las tierras bajas de la Amazonía, desde donde podrán retornar algún día (Allen 2002). En la Corónica de Guaman Poma, la Edad de los Inkas cierra el capítulo de las "edades" anteriores. Con la invasión europea, los inkas que hasta ese momento habían pertenecido a kay pacha, su propio tiempo, resultaron desplazados hacia un otro tiempo/pacha según el relato de Guaman Poma. Y la narración se sitúa, entonces, en un presente paralelo, en el pacha colonial, contemporáneo al mismo autor andino.

Mencioné inicialmente el dibujo "Pontifical Mundo" del mismo autor (1616: f. 42; ver Figura 4b), que, en un contexto de colonialidad evidente (se inserta en el capítulo de los reinados de los papas), muestra una estructura vertical similar a la de algunos qeros, En ese dibujo, las "Indias del Pirú" se ubican en una espacialidad Hanan, arriba, mientras que Castilla se ubica "en lo auajo de las Yndias", es decir en la posición subordinada o Urin. Varios investigadores proponen que esa distribución muestra una imagen del "orden social, del espacio, del tiempo y del sistema de gobierno" que había existido y el que debería ser, bajo el dominio español (Ossio 2008:

24 Es conocida como "Túnica Bandelier” y fue adquirida probablemente en la isla del Sol, en 1895 por Adolf Bandelier; actualmente está en el American Museum of Natural History (B1500). Publicada en Phipps 2005: 78-79.

25 Actualmente, en algunas danzas que se realizan en poblaciones vecinas al lago Titikaka, los bailarines llevan una pieza de tablillas de madera adornadas con plumas, las chakana o chakaña, sobre sus hombros. Chaka, en aymara, significa "puente" y chakaña es literalmente "escalera de palos" y su función ritual es unir los dos tiempos (adelante-atrás). En la danza Quena quena, el traje de los bailarines incluye un gran tocado de plumas en forma de arcoíris (el presente) y una coraza de piel de jaguar (el pasado). 
201; Prévôtel 2016). Wachtel (1976: 252), destacó la persistencia de un sistema de pensamiento andino que organizaba la percepción del mundo (y con ella, de los Andes prehispánicos y las Indias coloniales) reflejando un modelo conceptual que posee sus propias valoraciones del espacio y su organización. Y Adorno enfatizó que la creación de representaciones visuales sería una extensión de la tradición cultural propia del cronista (1991: 110) que se encuentra también en los dibujos de Pachacuti Yamqui y en los escritos de Garcilaso de la Vega (1991: 124). En definitiva, según propone Adorno, estaríamos en presencia de una matriz de compresión, que sería expresión de una ontología específica, la andina, para ordenar y simbolizar el espacio y las relaciones de quienes lo ocupan.

Como he planteado aquí, el espacio andino es inseparable del tiempo, y por lo tanto lo que está expresado en ese dibujo es asimismo una estructura ordenadora temporal "pasado-presente", a la cual se le pueden asignar diferentes posiciones y valoraciones. Lo que me interesa destacar es que se trata de una matriz de comprensión del momento colonial y de la memoria del pacha de los inkas que aparece en los escritos y dibujos de los autores andinos coloniales, en tejidos usados por la élite y en qeros elaborados en diversas partes del espacio andino cuzqueño y circum Titikaka.

\section{Conclusiones}

Si bien la obra monumental de Guaman Poma no fue conocida sino hasta el siglo XX, y por lo tanto no se le puede atribuir un impacto en la sociedad andina colonial de su época, con los qeros ocurrió algo distinto. Ellos sí alcanzaron una amplia difusión, fueron usados no solo por las élites, sino que también fueron adquiridos y transmitidos por otras personas, hombres y mujeres, que los conservaron o exhibieron como bienes de prestigio y ascenso social; fueron probablemente encomendados a los artesanos por autoridades locales menores para demostrar su raigambre andina antigua y se usaron profusamente en los numerosos rituales colectivos donde pudieron ser vistos por muchas personas (Ziolkowski 2009). Circularon por amplios espacios andinos, y en el siglo XVII surgieron nuevos estilos locales que incorporaron temáticas locales a la construcción de los textos visuales que ellos mostraban. Es posible, entonces, suponer que tuvieron un cierto grado de influencia al extremo de que también fueron empleados como parte de la iconografía que acompañó a las demandas por privilegios y reconocimientos políticos de las élites andinas, ya en el siglo XVIII, en el momento del "renacimiento inka" previo a la sublevación de Túpac Amaro II (Stasny 1993).

La instalación de la sociedad colonial en América tuvo como uno de sus componentes centrales un proceso de apropiación de las historias y memorias locales y su reescritura e inscripción ${ }^{26}$ en los dispositivos y prácticas traídas por los europeos; y el espacio andino no estuvo exento de esos procesos. Las sociedades americanas no fueron pasivas en estos procesos; por el contrario, hay evidencias de su activa participación, ya fuera para obtener un nuevo lugar en la naciente sociedad colonial o para defender antiguos o nuevos privilegios. Los relatos propios sobre las memorias locales fueron entonces también una de las herramientas empleadas por esas sociedades para construir sus propias narrativas, ya en un contexto colonial.

26 Para un estudio más profundo de este proceso, véase Cisterna 2010. 
Mientras los europeos desarrollaron una extensa campaña para recoger, registrar y escribir de manera "ordenada" y "verdadera" la historia de los inkas y el pasado de las sociedades andinas, esos mismos andinos apelaron tanto a sus propios sistemas de registro y comunicación, como a los traídos por los europeos para hacer circular sus propias voces.

Los qeros fueron uno de los sistemas de registro y comunicación que permitieron a las poblaciones andinas conservar un espacio de enunciaciones propias, en un contexto en que los cronistas españoles registraban, bajo sus lógicas, las historias y los conceptos de poder.

Ese fue el contexto "externo" de la escritura alfabética y de los textos visuales. Pero hubo un conflicto más profundo, relacionado con las formas de construcción de la representación y de las narrativas propias de cada una de esas culturas: el uso de las temporalidades en las cuales inscribir los relatos y darles sentido. La concepción cristiana, lineal o secuencial, organizada en tres unidades temporales -PASADO-PRESENTE-FUTURO - y en la cual el futuro es lo que otorga sentido al presente, coexistió con otra ontología, que unía en un mismo concepto, pacha, al tiempo y al espacio, y que concebía como pertinente la existencia simultánea de varios pacha.

\section{Referencias}

Adorno, Rolena. 1991. Guaman Poma. Literatura de resistencia en el Perú colonial. México: Siglo XXI Editores.

Allen, Catherine. 2002. «The Incas Have Gone inside: Pattern and Persistence in Andean Iconography». RES: Anthropology and Aesthetics 42: 180-203.

Anónimo. 2014 (1586). Arte y vocabulario en la lengua general del Perú. Edición interpretada y modernizada de Rodolfo Cerrón-Palomino. Lima: Instituto Riva-Agüero, Pontificia Universidad Católica del Perú.

Arzáns de Orsúa y Vela, Bartolomé. 1965 (1735). Historia de la Villa Imperial de Potosí. Edición y estudio preliminar de Lewis Hanke y Gunnar Mendoza. Providence: Brown University Press.

Betanzos, Juan de. 2015 (1551). Suma y narración de los Incas, en Juan de Betanzos y el Tahuantinsuyo, Francisco Hernández y Rodolfo Cerrón-Palomino, eds., pp. 107-440. Lima: Pontificia Universidad Católica del Perú.

Bouysse-Cassagne, Thérèse y Olivia Harris. 1987. «Pacha: en torno al pensamiento aymara», en Tres reflexiones sobre el pensamiento andino, Thérèse Bouysse-Cassagne, Tristan Platt y Verónica Cereceda, eds., pp. 11-60. La Paz: HISBOL.

Cabello Carro, Paz. 2006. «Continuidad prehispánica y mestizaje en Perú. Una historia de conquistadores narrada en un vaso de libaciones incaico». Anales del Museo de América 14: $145-174$.

Carbonell, Eliseu. 2004. Debates acerca de la antropología del tiempo. Barcelona: Universitat de Barcelona.

Cereceda, Verónica. 1990. «A partir de los colores de un pájaro...». Boletín del Museo Chileno de Arte Precolombino 4: 57-104.

Cisterna, Patricio. 2010. La memoria colonial. Procesos de inversión simbólica en la construcción de Occidente. Tesis Doctoral en Historia, mención Etnohistoria, Universidad de Chile. 
Cobo, Fray Bernabé. 1964 (1653). Historia del Nuevo Mundo. Biblioteca de Autores Españoles 91 y 92. Madrid: Ediciones Atlas.

Cummins, Thomas. 1993. "La representación en el siglo XVI: la imagen colonial del inca», en Mito y simbolismo en los Andes. La figura y la palabra, Henrique Urbano, comp., pp. 87-136. Cusco: Centro de Estudios Regionales Andinos «Bartolomé de Las Casas».

—. 1998. «Let Me See! Reading Is for Them: Colonial Andean Images and Objects 'como es costumbre tener los caciques Señores'», en Native Traditions in the Post Conquest World, Elizabeth Boone y Thomas Cummins, eds., pp. 91-148. Washington, D.C.: Dumbarton Oaks Research and Library Collection.

- 2004. Brindis con el Inca. La abstracción andina y las imágenes coloniales de los queros. Lima: Universidad Nacional Mayor de San Marcos, Universidad Mayor de San Andrés, Embajada de los Estados Unidos de América.

—. 2005. «La fábula y el retrato: imágenes tempranas del inca», en Los incas, reyes del Perú, Natalia Majluf, coord., pp. 1-42. Lima: Banco de Crédito del Perú.

Cummins, Thomas y Juan Ossio. 2013. «'Muchas veces dudé Real Mag. aceptar esta dicha ympressa': La tarea de hacer La Famossa Historia de los Reyes Incas de Fray Martín de Murúa», en Au miroir de l'Anthropologie historique. Mélanges offerts à Nathan Wachtel, Juan Carlos Garavaglia, Jacques Poloni-Simard y Gilles Rivière, dirs., pp. 151-170. Rennes: Presses Universitaires de Rennes.

Curatola, Marco y José Carlos de la Puente. 2013. «Contar concertando: quipus, piedritas y escritura en los Andes coloniales», en El quipu colonial. Estudios y materiales, Marco Curatola y José de la Puente, eds., pp. 193-243. Lima: Pontificia Universidad Católica del Perú.

Estenssoro, Juan Carlos. 1992. «Los bailes de los indios y el proyecto colonial». Revista Andina 20: 353-404.

-. 2005. «Construyendo la memoria: la figura del inca y el reino del Perú, de la conquista a Túpac Amaru II», en Los incas, reyes del Perú, Natalia Majluf, coord., pp. 93-173. Lima: Banco de Crédito del Perú.

Fernández, Gimena. 2015. «Una nueva relación entre escritura, historia y memoria en los Andes revelada por un cronista andino». Revista Andina 53: 113-136.

Finlay, Moses I. 1977. «Mito, memoria e historia», en Uso y abuso de la historia, Moses I. Finlay, pp. 11-44. Barcelona: Editorial Grijalbo.

Flores Ochoa, Jorge, Elizabeth Kuon y Roberto Samanez. 1997. «Vasos de madera. Región del Lago Titicaca». Arkinka 25: 102-111.

- 1998. Qeros. Arte inka en vasos ceremoniales. Lima: Banco de Crédito del Perú.

Gruzinski, Serge. 1991. La colonización de lo imaginario. Sociedades indígenas y occidentalización en el México español. Siglos XVI-XVIII. México: Fondo de Cultura Económica.

—. 1994. La guerra de las imágenes: de Cristóbal Colón a Blade Runner (1492-2019). México: Fondo de Cultura Económica.

Guaman Poma de Ayala, Felipe. 1616. Nueva corónica y buen gobierno. Biblioteca Real de Copenhague. http://www.kb.dk/permalink/2006/poma/info/es/frontpage.htm

Hardman, Martha. 1988. «Jaqi Aru: la lengua humana», en Raíces del mundo: el mundo aymara, Xavier Albó, comp., pp. 155-216. Madrid: Alianza Editorial.

Hernández Astete, Francisco. 2015. «La Cápac Cuna y la lucha por la memoria incaica», en Juan de Betanzos y el Tahuantinsuyo. Nueva edición de la Suma y narración de los Incas, Francisco Hernández Astete y Rodolfo Cerrón-Palomino, eds., pp. 55-71. Lima: Pontificia Universidad Católica del Perú.

Howard-Malverde, Rosaleen. 1988. «Talking about the Past: Tense and Testimonials in Quechua Narrative Discourse». Amerindia 13: 125-156. 
Husson, Jean-Philippe. 2001. La mort d'Ataw Wallpa ou La fin de l'Empire des Incas. Tragédie anonyme en langue quechua du milieu du XVIe siècle. Ginebra: Ediciones Patiño.

Korpisaari, Antti y Martti Pärssinen. 2005. Pariti: isla, misterio y poder. El tesoro cerámico de la cultura Tiwanaku. La Paz: República de Bolivia, República de Finlandia.

Liebscher, Verena. 1986. La iconografía de los qeros. Lima: G.H. Herrera Editores.

Lizárraga, Manuel. 2009. «Las élites andinas coloniales y la materialización de sus memorias particulares en los 'queros de la transición' (vasos de madera del siglo XVI)». Boletín del Museo Chileno de Arte Precolombino 14 (1): 37-53.

—. 2015. «Los queros y la imaginería andina colonial». Arqueología y Sociedad 29: 365-391.

Manga Quespi, Atuq E. 1994. «Pacha: un concepto andino de espacio y tiempo». Revista Española de Antropología Americana 24: 155-189.

Martínez C., José Luis. 2009. «Registros andinos al margen de la escritura: el arte rupestre colonial». Boletín del Museo Chileno de Arte Precolombino 14 (1): 9-35.

—. 2019. «'Las indias del Pirú en lo alto de España...’. Relaciones entre la Nueva Corónica y los qeros coloniales». Colonial Latin American Review 28 (1): 37-58. https://doi.org/ 10.1080/10609164.2019.1585082.

Martínez C., José Luis y Paula Martínez S. 2013. «Narraciones andinas coloniales. Oralidad y visualidad en los Andes». Journal de la Société des Américanistes 99 (2): 41-81.

Martínez C., José Luis, Carla Díaz, Constanza Tocornal y Verónica Arévalo. 2014. «Comparando las crónicas y los textos visuales andinos. Elementos para un análisis». Chungara 46 (1): 91-113.

Martínez C., José Luis, Carla Díaz y Constanza Tocornal. 2016a. «Inkas y antis, variaciones coloniales de un relato andino visual». Boletín del Museo Chileno de Arte Precolombino 21 (1): 7-23.

Martínez C., José Luis, Carla Díaz, Constanza Tocornal. Gabriela Acuña y Luz María Narbona. 2016b. «Qeros y discursos visuales en la construcción de la nueva sociedad colonial andina». Anuario de Estudios Americanos 73 (1): 15-43.

Martínez S., Paula. 2016. «Notas etnofilológicas sobre el volumen 3169 de la Biblioteca Nacional de España. Algunos aspectos sobre la escritura andina colonial». Boletín del Museo Chileno de Arte Precolombino 21 (1): 129-146.

Medinaceli, Ximena y Marcela Inch, coords. 2010. Pleitos y riqueza. Los caciques andinos en Potosí del siglo XVII. Transcripción y estudios del expediente de don Diego Chambilla contra los bienes de su administrador. Sucre: Ediciones del Archivo y Biblioteca Nacionales de Bolivia.

Mendoza, Javier. 2015. El espejo aymara. Ilusiones ideológicas en Bolivia. La Paz: Plural Editores.

Mignolo, Walter. 1992. «La colonización del lenguaje y de la memoria: complicidades de la letra, el libro y la historia», en Discursos sobre la «invención» de América, Iris Zavala, coord., pp. 183-220. Ámsterdam, Atlanta: Rodopi.

Mora, Gerardo y Andrea Goytia. 2016. «Los kerus vivos del ayllu Soraga y su participación en la fiesta de la Virgen del Rosario». Boletín del Museo Chileno de Arte Precolombino 21 (1): 47-60.

Murúa, fray Martín de. 2004 (1590). Historia del origen y genealogía real de los reyes ingas del Pirú, de sus hechos, costumbres, trajes y manera de gouierno. Manuscrito Galvin, edición facsímile a cargo de Juan Ossio. Madrid: Testimonio Compañía Editorial.

Ossio, Juan. 2008. En busca del orden perdido. La idea de la Historia en Felipe Guaman Poma de Ayala. Lima: Pontificia Universidad Católica del Perú. 
Otárola Alvarado, Carlos A. 1995. Qeros decorados del Qosqo. Cusco. Municipalidad del Qosqo.

Pärssinen, Martti y Jukka Kiviharju. 2004. Textos andinos. Corpus de textos khipu incaicos y coloniales, Tomo I. Madrid: Instituto Iberoamericano de Finlandia y Universidad Complutense de Madrid.

- 2010. Textos andinos. Corpus de textos khipu incaicos y coloniales, Tomo II. Madrid: Instituto Iberoamericano de Finlandia y Universidad Complutense de Madrid.

Phipps, Elena. 2005. «Rasgos de nobleza: los uncus virreinales y sus modelos incaicos», en Los incas, reyes del Perú, Natalia Majluf, coord., pp. 67-92. Lima: Banco de Crédito del Perú.

Platt, Tristan. 2015. «Refounding the House. Time, Politics, and Metallogenesis in a Colonial Aymara Coat of Arms», en The Meaning and Measure of Time in Mesoamerica and the Andes, Anthony F. Aveni, ed., pp. 239-273. Washington, D.C.: Dumbarton Oaks. Harvard University Press.

Platt, Tristan, Thérése Bouysse-Cassagne y Olivia Harris. 2006. Qaraqara-Charka. Mallku, Inka y rey en la provincia de Charcas (siglos XV-XVII). La Paz: Instituto Francés de Estudios Andinos, Plural Editores, University of St. Andrews, University of London, Interamerican Foundation, Fundación Cultural del Banco Central de Bolivia.

Prévôtel, Audrey. 2016. "Historia y memoria en la crónica de Guaman Poma de Ayala», en La memoria del mundo inca. Guaman Poma y la escritura de la Nueva Corónica, Jean-Philippe Husson, ed., pp. 301-326. Lima: Pontificia Universidad Católica del Perú.

Quipucamayos... 2004 (1542). Discurso sobre la descendencia y gobierno de los Incas, en Suma y narración de los Incas, de Juan de Betanzos, María del Carmen Martín Rubio, ed., pp. 357-395. Madrid: Ediciones Polifemo.

Ramos Gómez, Luis. 2001. «Mama Guaco y Chañan Curi Coca: un arquetipo o dos mujeres de la Historia Inca (reflexiones sobre la iconografía de un cuadro del Museo de la Universidad de San Antonio Abad del Cuzco)». Revista Española de Antropología Americana 31: 165-187.

-. 2002. «El choque de los Incas con los chancas en la iconografía de las vasijas lígneas coloniales», en El hombre y los Andes. Homenaje a Franklin Pease G.Y., Javier Flores Espinoza y Rafael Varón, eds., pp. 871-885. Lima: Instituto Francés de Estudios Andinos, Fondo Editorial de la Pontificia Universidad Católica del Perú.

—. 2008. "La escena del "Brindis con el Sol" en los queros o vasos de madera andinos de época colonial». Revista Española de Antropología Americana 38 (1): 139-166.

Rowe, John. 1985. «Probanza de los incas nietos de conquistadores». Histórica IX (2): 193245.

Salomon, Frank. 1994. «La textualización de la memoria en la América Andina: una perspectiva etnográfica comparada». América Indígena 54 (4): 229-261.

Santo Tomás, Domingo de. 1951 (1560). Lexicón o Vocabulario de la lengua general.... Edición Facsimilar. Lima: Universidad de San Marcos.

Sarmiento de Gamboa, Pedro. 2001 (1572). Historia de los Incas. Madrid: Miraguano Ediciones, Ediciones Polifemo.

Stasny, Francisco. 1993. «El arte de la nobleza inca y la identidad andina», en Mito y simbolismo en los Andes. La figura y la palabra, Henrique Urbano, comp., pp. 137-156. Cusco: Centro de Estudios Regionales Andinos "Bartolomé de las Casas".

Strecker, Matthias y Freddy Taboada. 2007. «Arte rupestre en la cuenca del lago Titicaca, Bolivia», en Actas del Primer Simposio Nacional de Arte Rupestre, Rainer Hostnig, Ma- 
thias Strecker y Jean Guffroy, eds., pp. 359-376. Actes et Mémoires 12. Lima: Instituto Francés de Estudios Andinos.

Taylor, Gerald, ed. 1987. Ritos y tradiciones de Huarochiri. Manuscrito quechua de comienzos del siglo XVII. Versión paleográfica, interpretación fonológica y traducción al castellano de Gerald Taylor. Historia Andina 12. Lima: Instituto de Estudios Peruanos, Instituto Francés de Estudios Andinos.

Urbano, Henrique. 1997. «Sexo, pinturas de los incas y taqui Oncoy. Escenas de la vida cotidiana en el Cuzco del siglo XVI». Revista Andina 29: 207-246.

Urton, Gary. 2004. Historia de un mito. Paqariqtambo y el origen de los inkas. Cuzco: Centro de Estudios Regionales Andinos «Bartolomé de Las Casas».

Ziòlkowski, Mariusz. 2009. «Lo realista y lo abstracto: observaciones acerca del posible significado de algunos tocapus (t'uqapu) 'figurativos'». Estudios Latinoamericanos 29: 307-334. 